\title{
PRODUCTION OF HYDROGEN FLUORIDE BY PROCESSING FLUORINE-CONTAINING WASTES AND BY-PRODUCTS OF MODERN INDUSTRIES
}

\author{
DMITRII S. PASHKEVICH \& ANTON V. MAMAEV \\ Peter the Great St Petersburg Polytechnic University, "New Chemical Products" Ltd., Russia
}

\begin{abstract}
This article shows the feasibility and possibility of developing a universal industrial method for producing hydrogen fluoride from fluorine-containing wastes and by-products of modern industries (depleted uranium hexafluoride, hydrofluorosilicic acid, ammonium bifluoride, carbon tetrafluoride, and other perfluorocarbons and hydrofluorocarbons, sulfur hexafluoride, nitrogen trifluoride, mixtures containing sodium hexafluoroaluminate, etc.) as alternatives to the conventional industrial method of natural calcium difluoride decomposition with sulfuric acid. As the main process method, we suggest fluoride reduction in a flame of hydrogen-containing fuel and oxygen-containing oxidant, due to the unique thermodynamic stability of hydrogen fluoride. The paper presents the results of thermodynamic calculation and experiments on the proposed method for various fluorides - uranium hexafluoride, carbon tetrafluoride, silicon tetrafluoride, ammonium bifluoride, etc. As a fuel, we consider methane, hydrogen and ammonia as an oxidizing agent, oxygen and air. For the case where water is present in the combustion products, we discuss various dehydrogenation options of hydrofluoric acid. We have demonstrated that the industrial cost hydrogen fluoride produced from the above-listed fluorides is approximately twofold lower than the same parameters for the conventional method of fluorite decomposition using sulfuric acid.

Keywords: fluorine-containing industrial wastes, hydrogen fluoride, combustion.
\end{abstract}

\section{INTRODUCTION}

Anhydrous hydrogen fluoride (AHF) (the HF content is not less than $99.9 \%, \mathrm{H}_{2} \mathrm{O}$, no more than $0.06 \%$ ) is the basic fluorinating agent in the production of industrial fluorine compounds: uranium fluorides in the nuclear fuel cycle (NFC), gaseous fluorine carriers $\left(\mathrm{NF}_{3}, \mathrm{CF}_{4}, \mathrm{C}_{2} \mathrm{~F}_{6}\right.$, etc.) for etching silicon in the semiconductor industry, fluoromonomers, freons, etc. [1].

Hydrogen fluoride is used as catalyst in alkylation processes in petrochemistry.

Hydrofluoric acid (aqueous solution of fluorine hydride) is used in the production of sodium hexafluoroaluminate for the aluminum industry, in the production of high purity quartz concentrate, when leaching rare metals from ores, first of all, tantalum and niobium.

Currently, the world AHF production is about 1.5 million tons per year, increasing annually by $5-10 \%$. Virtually the only AHF production method, which has been implemented in the modern industry, is sulfuric acid decomposition of natural fluorite concentrate (fluorspar, calcium difluoride $\mathrm{CaF}_{2}$ ) with the content of the main substance of more than $95 \%$ and with admixture of silicon dioxide not more than $2 \%$ :

$$
\mathrm{CaF}_{2 \text { sol }}+\mathrm{H}_{2} \mathrm{SO}_{4 \text { liquid }} \rightarrow \mathrm{CaSO}_{4 \text { sol }}+2 \mathrm{HF}_{\text {gas }}, \mathrm{T} \sim 250^{\circ} \mathrm{C} \text {. }
$$

Explored world reserves of fluorspars with a content of $\mathrm{CaF}_{2}$ of more than $35 \%$ are $60-70$ million tons. In the world market of fluorite, the share of China exceeds $50 \%$, but in many countries, including Russia, its reserves are limited. For example, the USA and France are the largest importers of this raw material. In recent years, the price of fluorite has increased, reaching $\$ 500$ per ton. 
Therefore, the development of AHF production methods based on other fluorinecontaining raw materials is an urgent task.

\section{FLUORINE-CONTAINING WASTES AND BY-PRODUCTS IN MODERN INDUSTRIES AND PROCESSING OF THE SAME}

Many industries generate fluorine-containing by-products and wastes: ${ }^{235} \mathrm{U}$-isotope depleted uranium hexafluoride (DUHF) in NFC; aqueous solution of hexafluorosilicic acid (AHFA) in the production of phosphate fertilizers from fluorapatite and in the production of high purity quartz concentrate; ammonium fluorides in the production of tantalum and niobium by leaching of ores with hydrofluoric acid; mixtures containing sodium hexafluoroaluminate in the production of aluminum by electrolysis; carbon tetrafluoride and others fluorocarbons in the production of organofluorine compounds, fluorine and aluminum; sulfur hexafluoride as a gaseous dielectric, nitrogen trifluoride, etc.

\subsection{Uranium hexafluoride}

DUHF is a by-product of the isotope uranium enrichment. Currently, around 2 million tons of this substance are accumulated worldwide, including up to 1 million tons in Russia. DUHF is stored in steel containers in open areas.

$\mathrm{UF}_{6}$ uranium hexafluoride (UHF) is a substance of the first class of hazard (its maximum permissible concentration in air is $\left.0.015 \mathrm{mg} \cdot \mathrm{m}^{-3}\right)$, volatile $\left(\mathrm{p}=0.1 \mathrm{MPa}\right.$ at $\left.56^{\circ} \mathrm{C}\right)$ and prone to hydrolysis. Therefore, the storage of significant amounts thereof is an environmental hazard.

Studies on the development of DUHF processing method has been conducted in different areas: the use of DUHF as a fluorinating agent for organochlorine compounds, recovering in plasma with water steam, recovering in a hydrogen-fluorine flame [2], [3].

The only known industrial DUHF processing technology has been developed by the French Areva company and represents a two-stage high-temperature hydrolysis [4], [5]:

$$
\begin{aligned}
& \mathrm{UF}_{6 \text { gas }}+2 \mathrm{H}_{2} \mathrm{O}_{\text {gas }} \rightarrow \mathrm{UO}_{2} \mathrm{~F}_{2 \text { sol }}+4 \mathrm{HF}_{\text {gas }}, \mathrm{T}=250-400^{\circ} \mathrm{C}, \\
& 3 \mathrm{UO}_{2} \mathrm{~F}_{2 \text { sol }}+3 \mathrm{H}_{2} \mathrm{O}_{\text {gas }}+\mathrm{H}_{2} \text { gas } \rightarrow \mathrm{U}_{3} \mathrm{O}_{8 \text { sol }}+6 \mathrm{HF}_{\text {gas }}+\mathrm{H}_{2} \mathrm{O}_{\text {gas }}, \mathrm{T}=450-600^{\circ} \mathrm{C} \text {. }
\end{aligned}
$$

At this temperature, the most stable uranium compound is its tetrafluoride $\mathrm{UF}_{4}$. To prevent $\mathrm{UF}_{4}$ generation and to completely regenerate fluorine, the eqns (2), (3) processes are carried out with an excess of water. Therefore, their product is an azeotropic aqueous solution of HF, that does not allow to close the nuclear fuel cycle on fluorine, as the production of natural uranium fluorides uses AHF.

In addition, the high temperature at equipment walls requires the use of exclusive construction materials whose composition is know-how of the Areva Company.

Hence, the above method is not widely used, and the DUHF accumulation in NFC still continues.

\subsection{Hydrofluorosilicic acid}

AHFA (aqueous solution of $\mathrm{H}_{2} \mathrm{SiF}_{6}$ ) is generated as a by-product during sulfuric acid decomposition of natural fluorapatite $3 \mathrm{Ca}_{3}\left(\mathrm{PO}_{4}\right)_{2} \mathrm{Ca}(\mathrm{Cl}, \mathrm{OH}, \mathrm{F})_{2}$ in the production of phosphoric acid in the phosphate fertilizers industry [6].

The fluorine content in fluorapatite is small: usually around $3 \%$, but the fluorapatite explored reserves are such that they contain about 1,000 million tons of fluorine, which is 
equivalent to about 2,000 million tons of fluorspar. Therefore, phosphate ores can become the main source of fluorine for future industrial needs.

One of the main impurities in fluorapatite is silicon dioxide. Therefore, in the sulfuric acid decomposition of fluorapatite, silicon tetrafluoride $\mathrm{SiF}_{4}(\mathrm{STF})$ is generated, which is hydrolyzed with formation of $\mathrm{H}_{2} \mathrm{SiF}_{6}$, and the main fluorine-containing by-product of phosphoric acid production is aqueous solution of AHFA with a concentration of $20-25 \%$.

Currently, the world production of extraction phosphoric acid is about 60 million tons in terms of $\mathrm{P}_{2} \mathrm{O}_{5}$ (the typical capacity of one plant is about 1 million tons per year in terms of $\mathrm{P}_{2} \mathrm{O}_{5}$ ), and the amount of fluorine in AHFA, representing a by-product, reaches 2 million tons per year.

AHFA is used to obtain $\mathrm{AlF}_{3}$ in the production of $\mathrm{Na}_{3} \mathrm{AlF}_{6}$ and to produce some fluorides and hexafluorosilicates: $\mathrm{NaF}, \mathrm{NH}_{4} \mathrm{~F} \cdot \mathrm{HF}, \mathrm{K}_{2} \mathrm{SiF}_{6}, \mathrm{Na}_{2} \mathrm{SiF}_{6},\left(\mathrm{NH}_{4}\right)_{2} \mathrm{SiF}_{6}$. Among the above fluorine salts, only $\mathrm{AlF}_{3}$ is in great demand.

Numerous attempts are being made to develop methods for AHF industrial production from AHFA, such as AHFA amination followed by treatment of the aqueous solution of ammonium fluoride with sodium fluoride and hydrogen fluoride recovery from sodium acid fluoride; AHFA amination and decomposition of ammonium fluoride with sulfuric acid, etc.

However, only the technology by the Buss Company has been currently brought to the level of industrial development, which consists in AHFA decomposition with concentrated sulfuric acid with the release of STF and its return to strengthen the initial AHFA and in thermal decomposition of the resulting fluorosulfonic acid with generation of hydrogen fluoride [7]. The main drawback of this technology is a significant amount of $75 \%$ sulfuric acid: up to $30 \mathrm{~kg}$ per $1 \mathrm{~kg}$ of AHF.

The Buss Company's method has been implemented in China; the production capacity is about 30,000 tons of AHF per year.

A significant amount of AHFA is currently neutralized with lime, and the resulting mixture of $\mathrm{CaF}_{2}$ and $\mathrm{SiO}_{2}$ is placed on industrial waste landfills.

\subsection{Ammonium bifluoride}

In the production of niobium and tantalum, leaching of ores is effected with hydrofluoric acid, producing aqueous solutions of hexafluorotanthal $\mathrm{HTaF}_{6}$ and hexafluoroniobium $\mathrm{HNbF}_{6}$ acids. Tantalum and niobium oxides are produced by treating acids with ammonia. $\mathrm{A}$ by-product of the process is ammonium bifluoride $\mathrm{NH}_{4} \mathrm{~F} \cdot \mathrm{HF}$ or aqueous solution of ammonium fluoride [8].

The world production of niobium is about 50,000 tons per year, and the amount of fluorine in ammonium fluorides can reach 60,000 tons per year. Ammonium fluorides are mainly neutralized with lime or stored in warehouses.

\subsection{Sodium hexafluoroaluminate}

In the production of aluminum by electrolysis, to increase the electrical conductivity of the melt, the latter is added with sodium hexafluoroaluminate $\mathrm{Na}_{3} \mathrm{AlF}_{6}$ (SHFA). As a result, waste mixtures are generated, consisting mainly of graphite (material of electrodes and electrolyzer lining), SHFA and aluminum oxides of three types: dust and electrolysis gas cleaning sludge, electrolyzer carbon foam, electrolyzer lining. Per 1 ton of aluminum, there are about $50 \mathrm{~kg}$ of waste fluorine-containing salts, mainly SHFA. The world production of aluminum is about 60 million tons, and the amount of fluorine discarded annually as solid waste is about 1.5 million tons [9]. 
Studies on the regeneration of fluorine from solid fluorine-containing wastes of the aluminum industry have been carried out in various areas. Leaching with sodium hydroxide has not found any industrial application due to the high cost of the resulting sodium fluoride. High-temperature hydrolysis of fluorine salts and high-temperature oxidation of carbon have also found no industrial application. Only $\mathrm{Na}_{3} \mathrm{AlF}_{6}$ regeneration from the electrolyte coal foam by flotation is currently used at the industrial level.

\subsection{Fluorocarbons, hydrofluorocarbons, sulfur hexafluoride, nitrogen trifluoride}

Carbon tetrafluoride (CTF) or tetrafluoromethane $\mathrm{CF}_{4}$ is generated as a waste in many industries in the production of fluorine (up to $1 \mathrm{~kg}$ per 1 ton of fluorine) and aluminum (about $0.3 \mathrm{~kg}$ per 1 ton of aluminum) by electrolysis (in fluoridation of graphite electrodes), in the production of fluoromonomers, perfluorinated liquids, freons, etc. CTF is a substance of the fourth hazard class (its maximum permissible concentration in air is $3,000 \mathrm{mg} \cdot \mathrm{m}^{-3}$ ), Therefore, in many industries, gaseous waste containing CTF are dispersed in the atmosphere. It is known that CTF is a greenhouse gas: its global warming potential is 6,500 times higher than that of carbon dioxide. In addition, the CTF lifetime in the atmosphere is about 50,000 years [10].

Sulfur hexafluoride (SHF) $\mathrm{SF}_{6}$ is also often dispersed in the atmosphere at depressurization of transformers. SHF, as well as CTF, is a substance of the fourth hazard class, the value of its global warming potential is 24,900 , its lifetime in the atmosphere is 3,200 years.

The foregoing concerns virtually all volatile perfluorocarbons, hydrofluorocarbons, as well as nitrogen trifluoride.

Therefore, dispersion of SHF and volatile perfluorocarbons $\left(\mathrm{CF}_{4}, \mathrm{C}_{2} \mathrm{~F}_{6}, \mathrm{C}_{3} \mathrm{~F}_{8}\right.$, etc.), hydrofluorocarbons $\left(1,1,1,2-\mathrm{C}_{2} \mathrm{~F}_{4} \mathrm{H}_{2}, \mathrm{C}_{2} \mathrm{~F}_{5} \mathrm{H}\right.$, etc. $)$, and $\mathrm{NF}_{3}$ in the atmosphere is inadmissible.

For processing CTF, the possibility of using plasmochemical reduction with water steam has been considered. However, operation in industrial conditions of such a complex electrical device as a plasma jet with a power supply system is too difficult.

\section{THE PROPOSED METHOD OF PROCESSING FLUORINE-CONTAINING WASTES WITH HYDROGEN FLUORIDE PRODUCTION}

It is advisable to consider the above fluorine-containing by-products and wastes as raw materials for AHF production.

Hydrogen fluoride is one of the most thermodynamically stable fluorides at $\mathrm{T}>1,000 \mathrm{~K}$ [11], [12]. Therefore, a universal method of regenerating fluorine from the above fluorinecontaining wastes may be their reduction in a flame of hydrogen-containing fuel and oxygencontaining oxidant [13]:

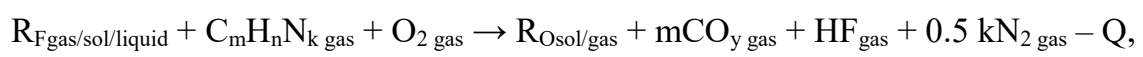

where $\mathrm{R}_{\mathrm{F}}$ - fluoride, $\mathrm{R}_{\mathrm{O}}$ - oxide or element, $\mathrm{C}_{\mathrm{m}} \mathrm{H}_{\mathrm{n}} \mathrm{N}_{\mathrm{k}}$ - hydrogen-containing substance, $\mathrm{m} \geq 0, \mathrm{n}>0, \mathrm{k} \geq 0, \mathrm{y}=1 ; 2, \mathrm{Q} \sim 10^{2-} 10^{3} \mathrm{~kJ}, \mathrm{~T}_{\mathrm{ad}} \geq 10^{3} \mathrm{~K}$.

The presence of hydrogen in the reaction zone should provide generation of hydrogen fluoride, whereas the presence of oxygen will contribute to oxide generation from elements contained in the original fluoride.

The use of high temperature in the reaction zone will ensure a high rate of chemical transformations, since it is known that, at a temperature above about $1,000^{\circ} \mathrm{C}$, kinetic impediments are associated with diffusion transfer of substances rather than with the reaction rate constant value. 
In the suggested method, the heat source for heating the components is contained in the initial substances themselves; this allows to maintain the temperature walls of the process equipment at a low level (at about $100^{\circ} \mathrm{C}$ to avoid condensation of hydrogen fluoride and, probably, water) and to use the available construction materials.

As a hydrogen-containing fuel, we suggest considering such commercially available substances as methane (and other hydrocarbons), ammonia, and hydrogen. It is possible also to use oxygen-containing substances, such as spirits, and hydrogen-containing compounds with other heteroatoms.

As an oxygen-containing oxidant, the easiest way is to use oxygen or air. In this case, oxygen is preferable in view of subsequent extracting hydrogen fluoride from the gas flow by condensation.

The thermal effect of the reaction should be selected based on calculation so that in the thermodynamically equilibrium mixture of substances, at a temperature of reaction products close to the adiabatic one, virtually the only fluoride should be HF.

\section{THE RESULTS OF THERMODYNAMIC CALCULATIONS}

\subsection{Uranium hexafluoride}

To determine the temperature range in which it is expedient to carry out the process of fluorine regeneration from UHF according to eqn (4), we carried out calculations of thermodynamically equilibrium composition of substances in the U-F-O-H element system, depending on temperature. The most thermally stable substances in the said element system are $\mathrm{UO}_{2}\left(\mathrm{~T}_{\text {fus }}=3148 \mathrm{~K}\right), \mathrm{UF}_{4}\left(\mathrm{~T}_{\text {fus }}=1309 \mathrm{~K}\right), \mathrm{UO}_{2} \mathrm{~F}_{2}\left(\mathrm{~T}_{\text {fus }}=1303 \mathrm{~K}\right), \mathrm{HF}$, and $\mathrm{H}_{2} \mathrm{O}$. The process pattern when using hydrogen as fuel is as follows:

$$
\begin{aligned}
\mathrm{x}_{1} \mathrm{UF}_{6} \text { gas } & +\mathrm{x}_{2} \mathrm{H}_{2 \text { gas }}+\mathrm{x}_{3} \mathrm{O}_{2 \text { gas }} \\
& \rightarrow \mathrm{y}_{1} \mathrm{UO}_{2 \text { sol }}+\mathrm{y}_{2} \mathrm{UO}_{4 \text { sol/liq }}+\mathrm{y}_{3} \mathrm{UO}_{2} \mathrm{~F}_{2 \text { sol/liq }}+\mathrm{y}_{4} \mathrm{HF}_{\text {gas }}+\mathrm{y}_{5} \mathrm{H}_{2} \mathrm{O}_{\text {gas. }} .
\end{aligned}
$$

The basis for the calculation procedure was the search of $y_{n}$ values at which the sum of Gibbs energies for substances in the right part of eqn (5) is minimal with the given values of $x_{n}$.

The calculation results are given in Fig. 1. Having analyzed these results, we can conclude that, at a temperature above $1,100 \mathrm{~K}$ in a thermodynamically equilibrium mixture, virtually the only fluorine-containing substance is $\mathrm{HF}$, virtually the only uranium-containing substance is $\mathrm{UO}_{2}$, the content of $\mathrm{UF}_{4}$ and $\mathrm{UO}_{2} \mathrm{~F}_{2}$ not exceeding $0.3 \%$ and $0,1 \%$, respectively.

Therefore, in order to obtain a high degree of fluorine regeneration from uranium fluorides, it is necessary to choose values of $x_{n}$ in eqn (5) so that the temperature of the process products should be above $1,100 \mathrm{~K}$.

For $\mathrm{H}_{2}, \mathrm{CH}_{4}$, and $\mathrm{NH}_{3}$ as a fuel and oxygen and air as an oxidant, we calculated the adiabatic temperature of products and the temperature, taking into account the thermal radiation of a heterogeneous torch, under the assumption that radiation losses are up to $40 \%$. The calculation results are given in Table 1.

Table 1 show that temperatures $\mathrm{T}_{\mathrm{ad}}$ and $\mathrm{T}_{\mathrm{rad}}$ are significantly higher than $1,100 \mathrm{~K}$.

When cooling the products according to eqn (5) below 1,100 K, there will be the following reaction:

$$
\mathrm{UO}_{2 \text { sol }}+4 \mathrm{HF}_{\text {gas }} \rightarrow \mathrm{UF}_{4 \text { sol }}+2 \mathrm{H}_{2} \mathrm{O}_{\text {gas }}
$$

The change in Gibbs energy in this process is $\Delta \mathrm{G}<0$ at a temperature below $1,045 \mathrm{~K}$. 


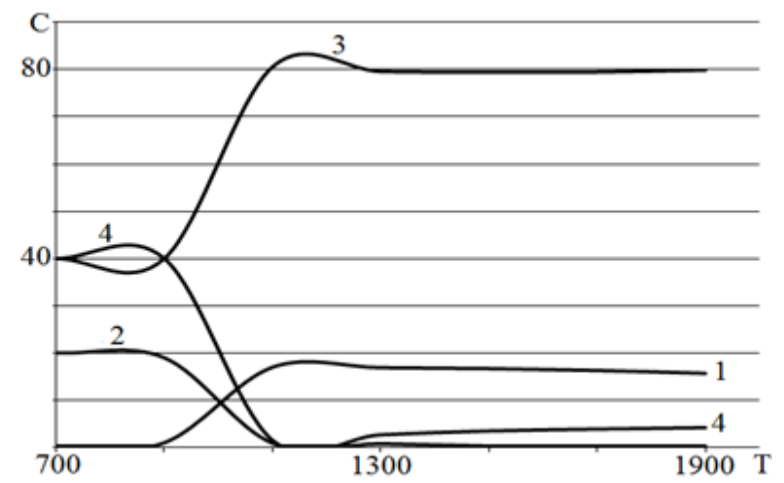

Figure 1: Concentration of substances $\mathrm{C}(\mathrm{mol} . \%)$ in a thermodynamically equilibrium mixture of compounds in the U-F-O-H element system with $\mathrm{x}_{1}=1, \mathrm{x}_{2}=3$, $\mathrm{x}_{3}=1$ depending on temperature $\mathrm{T}(\mathrm{K})$ : $1-\mathrm{C}_{\mathrm{UO} 2}, 2-\mathrm{C}_{\mathrm{UF} 4}, 3-\mathrm{C}_{\mathrm{HF}}, 4-\mathrm{C}_{\mathrm{H} 2 \mathrm{O}}$.

Table 1: Thermal effects Q and the temperature of UHF reduction reaction products - the adiabatic $T_{a d}$ and taking into account the thermal radiation of the heterogeneous torch $\mathrm{T}_{\mathrm{rad}}$ at the initial components temperature of $400 \mathrm{~K}$.

\begin{tabular}{|c|l|c|c|c|}
\hline No. & Reaction & $\mathrm{Q}, \mathrm{kJ}$ & $\begin{array}{c}\mathrm{T}_{\mathrm{ad}}, \\
\mathrm{K}\end{array}$ & $\begin{array}{c}\mathrm{T}_{\text {rad, }} \\
\mathrm{K}\end{array}$ \\
\hline 1 & $\mathrm{UF}_{6 \text { gas }}+3 \mathrm{H}_{2 \text { gas }}+\mathrm{O}_{2 \text { gas }} \rightarrow \mathrm{UO}_{2 \text { sol }}+6 \mathrm{HF}_{\text {gas }}$ & 583 & 2,560 & 1,680 \\
\hline 2 & $\mathrm{UF}_{6 \text { gas }}+2 \mathrm{NH}_{3 \text { gas }}+\mathrm{O}_{2 \text { gas }} \rightarrow \mathrm{UO}_{2 \text { sol }}+6 \mathrm{HF}_{\text {gas }}+\mathrm{N}_{2 \text { gas }}$ & 490 & 2,070 & 1,390 \\
\hline 3 & $\mathrm{UF}_{6 \text { gas }}+1.5 \mathrm{CH}_{4 \text { gas }}+2.5 \mathrm{O}_{2 \text { gas }} \rightarrow \mathrm{UO}_{2 \text { sol }}+6 \mathrm{HF}_{\text {gas }}+1.5 \mathrm{CO}_{2 \text { gas }}$ & 1,061 & 3,260 & 2,050 \\
\hline 4 & $\mathrm{UF}_{6 \text { gas }}+3 \mathrm{H}_{2 \text { gas }}+\mathrm{O}_{2 \text { gas }}+4 \mathrm{~N}_{2} \rightarrow \mathrm{UO}_{2 \text { sol }}+6 \mathrm{HF}_{\text {gas }}+4 \mathrm{~N}_{2 \text { gas }}$ & 583 & 1,870 & 1,300 \\
\hline
\end{tabular}

The reaction rate according to eqn (6) is limited by the HF diffusion through the layer of $\mathrm{UF}_{4}$ on the surface of a $\mathrm{UO}_{2}$ particle; therefore, the typical process time according to eqn (6) at $1,000 \mathrm{~K}$ is tens of minutes and tens of hours at $500 \mathrm{~K}$. To minimize the reaction depth eqn (6), it is necessary to ensure the time for cooling the reaction mixture down to $500 \mathrm{~K}$ at the level of at hundredths of a second, which can be achieved with a certain configuration of the heat exchanger, located after the flame reactor, and separation of the solid and gas phases at this temperature.

\subsection{Hydrofluorosilicic acid}

A fluorine-containing by-product of the phosphate fertilizers production is AHFA, which exists only in aqueous solution, and when concentrated and heated, is decomposed to form $\mathrm{SiF}_{4}(\mathrm{STF})$.

In the $\mathrm{Si}-\mathrm{H}-\mathrm{F}-\mathrm{O}$ element system, the most stable substances are STF, silicon dioxide $\mathrm{SiO}_{2}$ (SDO), water, and hydrogen fluoride. The change in Gibbs energy for the STF hydrolysis reaction

$$
\mathrm{SiF}_{4 \text { gas }}+2 \mathrm{H}_{2} \mathrm{O}_{\text {gas }} \rightarrow \mathrm{SiO}_{2 \text { sol }}+4 \mathrm{HF}_{\text {gas }}
$$

is less than zero at a temperature above $1,085 \mathrm{~K}$. Therefore, it is advisable to carry out the STF reduction in a flame of hydrogen-containing fuel and oxygen-containing oxidant above this temperature. 
At a temperature above $1,000 \mathrm{~K}$, there are three SDO crystalline modifications: $\beta$-quartz, $\beta$-tridimite and $\beta$-cristobalite. The values of thermodynamic functions - standard generation enthalpy and entropy and heat capacity - for these substances differ by a few percent. The calculation was made for $\beta$-cristobalite.

Usually, the $\mathrm{H}_{2} \mathrm{SiF}_{6}$ concentration in aqueous solution is about $20 \%$ and, as a result of the process

$$
\begin{aligned}
& \mathrm{SiF}_{4 \text { gas }}+2 \mathrm{HF}_{\text {gas }}+\mathrm{x}_{1} \mathrm{H}_{2} \mathrm{O}_{\text {liquid }}+\mathrm{x}_{2} \mathrm{CH}_{4} \text { gas }+\mathrm{x}_{3} \mathrm{O}_{2} \text { gas } \\
& \rightarrow \mathrm{SiO}_{2 \text { sol }}+6 \mathrm{HF}_{\text {gas }}+\mathrm{y}_{1} \mathrm{CO}_{2 \text { gas }}+\mathrm{y}_{2} \mathrm{H}_{2} \mathrm{O}_{\text {gas }},
\end{aligned}
$$

where $\mathrm{x}_{3}=\mathrm{x}_{2}, \mathrm{y}_{1}=\mathrm{x}_{2}, \mathrm{y}_{2}=\mathrm{x}_{1}+2 \mathrm{x}_{2}-2$, with $\mathrm{x}_{1}=30$ (the fluorine content in the solution is $16.7 \%$ ), at the reagents initial temperature of $400 \mathrm{~K}$ and the temperature $\mathrm{T}_{\mathrm{rad}}=1,500 \mathrm{~K}$, the hydrogen fluoride concentration in the mixture is $10 \%\left(\mathrm{y}_{2}=37\right)$.

To increase the hydrogen fluoride concentration in the mixture with water, to reduce the costs of producing an azeotropic aqueous solution of hydrogen fluoride (40\%) by rectification and to produce $\mathrm{AHF}$, it is advisable to separate water contained in the AHFA by its neutralization with alkaline agents to produce hexafluorosilicates that are slightly soluble in water, for example:

$$
\begin{aligned}
\mathrm{H}_{2} \mathrm{SiF}_{6}+2 \mathrm{NaOH} & =\mathrm{Na}_{2} \mathrm{SiF}_{6}+2 \mathrm{H}_{2} \mathrm{O}, \\
\mathrm{H}_{2} \mathrm{SiF}_{6}+\mathrm{CaO} & =\mathrm{CaSiF}_{6}+\mathrm{H}_{2} \mathrm{O}, \\
\mathrm{H}_{2} \mathrm{SiF}_{6}+2 \mathrm{NH}_{4} \mathrm{OH} & =\left(\mathrm{NH}_{4}\right)_{2} \mathrm{SiF}_{6}+2 \mathrm{H}_{2} \mathrm{O} .
\end{aligned}
$$

Hexafluorosilicates are thermally instable substances, and when heated, they are decomposed to form volatile fluorine compounds:

$$
\begin{gathered}
\mathrm{Na}_{2} \mathrm{SiF}_{6 \text { sol }} \rightarrow 2 \mathrm{NaF}_{\text {sol }}+\mathrm{SiF}_{4 \text { gas }}, \mathrm{T} \sim 900 \mathrm{~K}, \\
\mathrm{CaSiF}_{6 \text { sol }} \rightarrow \mathrm{CaF}_{2 \text { gas }}+\mathrm{SiF}_{4 \text { gas }}, \mathrm{T} \sim 650 \mathrm{~K}, \\
\left(\mathrm{NH}_{4}\right)_{2} \mathrm{SiF}_{6 \text { sol }} \rightarrow\left(\mathrm{NH}_{4}\right)_{2} \mathrm{SiF}_{6 \text { gas }} \rightarrow 2 \mathrm{NH}_{3 \text { gas }}+2 \mathrm{HF}_{\text {газ }}+\mathrm{SiF}_{4 \text { gas }}, \mathrm{T} \sim 550 \mathrm{~K} .
\end{gathered}
$$

The resulting volatile fluorides processed in a flame of hydrogen-containing fuel and oxygencontaining oxidant; the calculation results for thermal effects and the reaction product temperatures are given in Table 2. In case of ammonium hexafluorosilicate, the fuel (of the ammonium group) is contained in the salt.

The process products temperature in Table 2 significantly exceeds $1,085 \mathrm{~K}$.

It is also possible to carry out the hexafluorosilicate reduction in the combustion mode and without preliminary hexafluorosilicate thermal decomposition by feeding powder into the combustion zone, the reaction product temperature values in this case significantly exceeding $1,085 \mathrm{~K}$, see processes according to eqns (5), (6) in Table 2.

When the reaction products are cooled below $1,085 \mathrm{~K}$, there will be $\mathrm{SiO}_{2}$ fluoridation by hydrogen fluoride. In this case, $\mathrm{SiF}_{4}\left(\mathrm{~T}_{\text {boil }}=-65^{\circ} \mathrm{C}\right)$ will be partly removed from the $\mathrm{SiO}_{2}$ surface, without forming a solid protective layer on its surface, as is the case for $\mathrm{UO}_{2}$ and $\mathrm{UF}_{4}$. Therefore, it is advisable to consider the option of removing silicon prior to the $\mathrm{SiF}_{4}$ silicon processing stage in flame. It can be done by producing $\mathrm{NH}_{4} \mathrm{~F}$ solution at the stage of processing AHFA aqueous solution by ammonia water or ammonia:

$$
\mathrm{H}_{2} \mathrm{SiF}_{6 \text { solution }}+6 \mathrm{NH}_{4} \mathrm{OH}_{\text {liquid }} \rightarrow 6 \mathrm{NH}_{4} \mathrm{~F}_{\text {solution }}+\mathrm{SiO}_{2 \text { sol }}+4 \mathrm{H}_{2} \mathrm{O}_{\text {liquid }} \text {, }
$$

from which solid ammonium bifluoride is produced by evaporation, which is then combusted in oxygen in gaseous, liquid, or solid phase, for example: 
Table 2: Thermal effects Q and STF and hexafluorosilicates reduction reaction products temperatures - adiabatic $\mathrm{T}_{\mathrm{ad}}$ and taking into account the thermal radiation of a heterogeneous torch $\mathrm{T}_{\mathrm{rad}}$ at the initial component temperature of $400 \mathrm{~K}$.

\begin{tabular}{|c|l|c|c|c|}
\hline No. & Reaction & Q, $\mathrm{kJ}$ & $\mathrm{T}_{\mathrm{ad}}, \mathrm{K}$ & $\mathrm{T}_{\mathrm{rad}}, \mathrm{K}$ \\
\hline 1 & $\begin{array}{l}\mathrm{SiF}_{4 \text { gas }}+2 \mathrm{NH}_{2 \text { gas }}+2 \mathrm{HF}_{\text {gas }}+1.5 \mathrm{O}_{2 \text { gas }} \rightarrow \\
\rightarrow \mathrm{N}_{2 \text { gas }}+\mathrm{SiO}_{2 \text { sol }}+6 \mathrm{HF}_{\text {gas }}+\mathrm{H}_{2} \mathrm{O}_{\text {gas }}\end{array}$ & 539 & 2120 & 1510 \\
\hline 2 & $\begin{array}{l}\mathrm{SiF}_{4 \text { gas }}+\mathrm{CH}_{4 \text { gas }}+2 \mathrm{O}_{2 \text { gas }} \rightarrow \\
\rightarrow \mathrm{SiO}_{2 \text { sol }}+\mathrm{CO}_{2 \text { gas }}+4 \mathrm{HF}_{\text {gas }}\end{array}$ & 703 & 3400 & 2300 \\
\hline 3 & $\mathrm{SiF}_{4 \text { gas }}+2 \mathrm{H}_{2 \text { gas }}+\mathrm{O}_{2 \text { gas }} \rightarrow \mathrm{SiO}_{2 \text { sol }}+4 \mathrm{HF}_{\text {gas }}$ & 384 & 2540 & 1760 \\
\hline 5 & $\begin{array}{l}\mathrm{SiF}_{4} \text { gas } \\
\rightarrow \mathrm{SiO}_{2 \text { sol }}+4 \mathrm{H}_{2 \text { gas }}+\mathrm{O}_{2 \text { gas }}+4 \mathrm{~N}_{2 \text { gas }} \rightarrow\end{array}$ & 384 & 1760 & 1270 \\
\hline 6 & $\begin{array}{l}\mathrm{Na}_{2} \mathrm{SiF}_{6 \text { sol }}+\mathrm{CH}_{4 \text { gas }}+2 \mathrm{O}_{2 \text { gas }} \rightarrow \\
\rightarrow 2 \mathrm{NaF}_{\text {sol }}+\mathrm{SiO}_{2 \text { sol }}+4 \mathrm{HF}_{\text {gas }}+\mathrm{CO}_{2 \text { gas }}\end{array}$ & 626 & 2220 & 1580 \\
\hline $\begin{array}{l}\mathrm{CaSiF}_{6 \text { sol }}+\mathrm{CH}_{4 \text { gas }}+2 \mathrm{O}_{2 \text { gas }} \rightarrow \\
\rightarrow \mathrm{CaF}_{2 \text { sol }}+\mathrm{SiO}_{2 \text { sol }}+4 \mathrm{HF}_{\text {gas }}+\mathrm{CO}_{2 \text { gas }}\end{array}$ & 708 & 2590 & 1820 \\
\hline
\end{tabular}

$$
\mathrm{NH}_{3 \text { gas }}+2 \mathrm{HF}_{\text {gas }}+0.75 \mathrm{O}_{2 \text { gas }} \rightarrow 0,5 \mathrm{~N}_{2 \text { gas }}+2 \mathrm{HF}_{\text {gas }}+1.5 \mathrm{H}_{2} \mathrm{O}_{\text {gas }}-317 \mathrm{~kJ} \text {. }
$$

For the process according to eqn (16) $\mathrm{T}_{\mathrm{ad}}=2710 \mathrm{~K}$ at $\mathrm{T}_{0}=500 \mathrm{~K}$. In a thermodynamically equilibrium mixture of substances in the N-H-F-O element system, the only fluorinecontaining substance is hydrogen fluoride, which eliminates the need for prompt cooling and separating the reaction products.

\subsection{Ammonium bifluoride}

Ammonium bifluoride and other ammonium fluorides, that are generated as by-products in the tantalum and niobium production, can be processed in combustion mode with production of hydrogen fluoride, similarly to eqn (16).

\subsection{Sodium hexafluoroaluminate}

In the production of aluminum by electrolysis, fluorine-containing mixtures are generated as a waste, consisting mainly of SHFA, carbon, and $\mathrm{SiO}_{2}$.

At a temperature above $1,200^{\circ} \mathrm{C}$, SHFA is decomposed with generation of $\mathrm{AlF}_{3}$ and $\mathrm{NaF}$. The calculations show that hydrolysis of sodium fluoride according to

$$
2 \mathrm{NaF}_{\text {sol }}+\mathrm{H}_{2} \mathrm{O}_{\text {gas }} \rightarrow \mathrm{Na}_{2} \mathrm{O}_{\text {sol }}+2 \mathrm{HF}_{\text {gas }}
$$

is thermodynamically forbidden in the entire actual temperature range for this reaction $\Delta \mathrm{G}>$ 0 , where $\mathrm{G}$ is Gibbs free energy.

At the same time, for the reaction

$$
2 \mathrm{AlF}_{3 \text { sol }}+\mathrm{H}_{2} \mathrm{O}_{\text {gas }} \rightarrow \mathrm{Al}_{2} \mathrm{O}_{3 \text { sol }}+6 \mathrm{HF}_{\text {gas }}
$$

$\Delta \mathrm{G}<0$ for the temperature range above $1200 \mathrm{~K}$.

Therefore, carrying out the process of cryolite reduction in the flame of hydrogencontaining fuel and oxygen-containing oxidant, we can regenerate up to $50 \%$ of fluorine contained therein. For example, when carrying out the process (stoichiometric coefficients of SHFA, carbon, and aluminum oxide approximately correspond to the ratio of these substances in solid waste) 


$$
\begin{aligned}
\mathrm{Na}_{3} \mathrm{AlF}_{6 \text { sol }}+10 \mathrm{C}_{\text {sol }}+1, & 5 \mathrm{Al}_{2} \mathrm{O}_{3 \text { sol }}+0,75 \mathrm{CH}_{4 \text { gas }}+11,5 \mathrm{O}_{2 \text { gas }} \\
\rightarrow & 3 \mathrm{NaF}_{\text {gas } / \text { liquid }}+2 \mathrm{Al}_{2} \mathrm{O}_{3 \text { sol }}+3 \mathrm{HF}_{\text {gas }}+10.75 \mathrm{CO}_{2} \text { gas }
\end{aligned}
$$

the temperatures $\mathrm{T}_{\mathrm{ad}}$ and $\mathrm{T}_{\mathrm{rad}}$ are 3,430 and 3,090 K, respectively.

4.5 Fluorocarbons, fluorocarbon, sulfur hexafluoride, nitrogen trifluoride

In the C-H-F-O element system, the only thermodynamically stable fluoride is HF; therefore, processing fluorocarbon according to the following pattern:

$$
\mathrm{CF}_{4 \text { gas }}+2 \mathrm{H}_{2 \text { gas }}+\mathrm{O}_{2 \text { gas }} \rightarrow \mathrm{CO}_{2 \text { gas }}+4 \mathrm{HF}_{\text {gas }}-534 \mathrm{~kJ}, \mathrm{~T}_{\mathrm{ad}} \sim 3,000 \mathrm{~K},
$$

seems very promising.

CTF is the most thermally stable substance among organic fluorine compounds. Therefore, the suggested principle can be extended to various chlorofluorohydrocarbons:

$$
\mathrm{C}_{\mathrm{x}} \mathrm{H}_{\mathrm{y}} \mathrm{F}_{\mathrm{z}} \mathrm{Cl}_{\mathrm{w} \text { gas }}+\mathrm{C}_{\mathrm{m}} \mathrm{H}_{\mathrm{n}} \mathrm{N}_{\mathrm{kgas}}+\mathrm{O}_{2} \text { gas } \rightarrow \mathrm{CO}_{2} \text { gas }+\mathrm{HF}_{\text {gas }}+\mathrm{HCl}_{\text {gas }}+0.5 \mathrm{kN}_{2} \text { gas }-\mathrm{Q} \text {, }
$$

including solid ones, such as polytetrafluoroethylene:

$$
\left(\mathrm{C}_{2} \mathrm{~F}_{4}\right)_{\mathrm{n} \text { gas }}+\mathrm{nCH}_{4 \text { gas }}+3 \mathrm{nO}_{2} \rightarrow 3 \mathrm{nCO}_{2} \text { gas }+4 \mathrm{nHF}-1539 \mathrm{~kJ}, \mathrm{~T}_{\mathrm{ad}} \approx 4,700 \mathrm{~K} .
$$

In the S-F-O-H and N-F-H element systems, the only thermodynamically stable fluoride is $\mathrm{HF}$, therefore processing $\mathrm{SF}_{6}$ and $\mathrm{NF}_{3}$ in the combustion mode allows to produce $\mathrm{HF}$ :

$$
\begin{gathered}
\mathrm{SF}_{6 \text { gas }}+3 \mathrm{H}_{2 \text { gas }}+\mathrm{O}_{2 \text { gas }} \rightarrow \mathrm{SO}_{2 \text { gas }}+6 \mathrm{HF}_{\text {gas }}-717 \mathrm{~kJ}, \mathrm{~T}_{\mathrm{ad}} \approx 3,000 \mathrm{~K}, \\
\mathrm{NF}_{3 \text { gas }}+1,5 \mathrm{H}_{2 \text { gas }} \rightarrow 0,5 \mathrm{~N}_{2 \text { gas }}+3 \mathrm{HF}_{\text {gas }}-688 \mathrm{~kJ}, \mathrm{~T}_{\mathrm{ad}} \approx 5,500 \mathrm{~K} .
\end{gathered}
$$

In the process according to eqn (24), there is no need to use any oxidizing agent, as the reduction of nitrogen trifluoride with a hydrogen-containing substance is accompanied by a very high thermal effect.

\section{EXPERIMENTAL STUDIES}

\subsection{Laboratory facility}

For experimental activities according to eqn (4), a laboratory facility has been constructed at the "Applied Chemistry" Russian Research Center, St Petersburg, Russian Federation.

The main element of the facility is a "combustion tunnel"-type thermostated nickel reactor with an internal diameter of $40 \mathrm{~mm}$, equipped with medium thermocouples without protective covers and electric spark and filament spirals flame front initiation systems.

CTF is one of the most thermally stable volatile fluorides, not prone to hydrolysis. Therefore, on the constructed facility, we investigated the composition of the products of its processing in a flame of hydrogen-containing fuel and oxygen. In these products, we found $\mathrm{CF}_{4}, \mathrm{O}_{2}, \mathrm{H}_{2}, \mathrm{CH}_{4}, \mathrm{CO}, \mathrm{CO}_{2}, \mathrm{HF}, \mathrm{H}_{2} \mathrm{O}$, see Table 3. Carbon fluorides and carbon oxyfluorides, other than $\mathrm{CF}_{4}$, have not been found.

We studied $\mathrm{CF}_{4}$ and $\mathrm{NF}_{3}$ mixture processing $\left(\mathrm{NF}_{3}\right.$ production waste classified as $\left.4 \mathrm{~N}\right)$ by hydrogen and by hydrogen and fluorine in the combustion mode; we established that the reaction products contain carbon and $\mathrm{C}_{2} \mathrm{~F}_{4}$, see Table 4:

$$
\begin{aligned}
\mathrm{x}_{1} \mathrm{CF}_{4} \text { gas } & \mathrm{x}_{2} \mathrm{NF}_{3 \text { gas }}+\mathrm{x}_{3} \mathrm{H}_{2} \text { gas } \\
& \rightarrow \mathrm{y}_{1} \mathrm{CF}_{4} \text { gas } \\
& \mathrm{y}_{2} \mathrm{NF}_{3 \text { gas }}+\mathrm{y}_{3} \mathrm{C}_{\mathrm{TB}}+\mathrm{y}_{4} \mathrm{~N}_{2 \text { gas }}+\mathrm{y}_{5} \mathrm{HF}_{\text {gas }}+\mathrm{y}_{6} \mathrm{C}_{2} \mathrm{~F}_{4 \text { gas }} .
\end{aligned}
$$


Table 3: Concentration of substances $\mathrm{C}$ in $\mathrm{CF}_{4}$ processing products in a $\mathrm{H}_{2}$ and $\mathrm{O}_{2}$ flame and $\mathrm{CH}_{4}$ and $\mathrm{O}_{2}$ and $\mathrm{CF}_{4}$ conversion $\mathrm{K}$ depending on component consumption $\mathrm{W}$.

\begin{tabular}{|c|c|c|c|c|c|c|c|c|c|c|c|c|}
\hline \multicolumn{4}{|c|}{$\mathrm{W}, \mathrm{cm}^{3} \cdot \mathrm{s}^{-1}$} & \multicolumn{7}{|c|}{$\mathrm{C}$, weight \% } & $\mathrm{K}$, \\
\cline { 1 - 11 } $\mathrm{CF}_{4}$ & $\mathrm{O}_{2}$ & $\mathrm{H}_{2}$ & $\mathrm{CH}_{4}$ & $\mathrm{CF}_{4}$ & $\mathrm{O}_{2}$ & $\mathrm{H}_{2}$ & $\mathrm{CH}_{4}$ & $\mathrm{CO}_{2}$ & $\mathrm{CO}$ & $\mathrm{HF}$ & $\mathrm{H}_{2} \mathrm{O}$ & $\%$ \\
\hline 16 & 22 & 44 & - & 7.8 & 2.6 & - & - & 19.6 & 3.6 & 52.5 & 14.7 & 89 \\
\hline 17 & 22 & 39 & - & 11.2 & 0.5 & - & - & 22.3 & - & 49.4 & 16.7 & 83 \\
\hline 17 & 17 & 40 & - & 30.5 & 5.5 & 0.6 & - & 9.1 & - & 38.5 & 15.8 & 66 \\
\hline 4 & 8 & - & 5 & 12.2 & 2.2 & 0.1 & 0.2 & 14.7 & - & 39.2 & 31.5 & 78 \\
\hline
\end{tabular}

Table 4: $\mathrm{CF}_{4}$ and $\mathrm{NF}_{3}$ conversion $\mathrm{K}, \mathrm{C}_{2} \mathrm{~F}_{4}$ amount $\eta$ in $\%$ of the possible value, and $\mathrm{T}_{\mathrm{ad}}$ depending on the component consumption $\mathrm{W}$ when processing the $\mathrm{CF}_{4}$ and $\mathrm{NF}_{3}$ mixture by hydrogen and by hydrogen and fluorine in the combustion mode.

\begin{tabular}{|c|c|c|c|c|c|c|c|}
\hline \multicolumn{4}{|c|}{$\mathrm{W}, \mathrm{cm}^{3} \cdot \mathrm{s}^{-1}$} & \multicolumn{2}{|c|}{$\mathrm{K}, \%$} & \multirow{2}{*}{$\eta, \%$} & \multirow{2}{*}{$\mathrm{T}_{\mathrm{ad}}, \mathrm{K}$} \\
\hline $\mathrm{H}_{2}$ & $\mathrm{NF}_{3}$ & $\mathrm{CF}_{4}$ & $\mathrm{~F}_{2}$ & $\mathrm{NF}_{3}$ & $\mathrm{CF}_{4}$ & & \\
\hline 7.7 & 3.1 & 0.3 & - & 100 & 100 & - & 4,586 \\
\hline 8.3 & 2.4 & 0.9 & - & 100 & 92.9 & 0.7 & 3,828 \\
\hline 8.7 & 1.9 & 1.4 & - & 100 & 89.1 & 20.9 & 3,160 \\
\hline 8.8 & 2.0 & 1.5 & - & 97.3 & 85.0 & 38.1 & 2,980 \\
\hline 8.9 & 1.6 & 1.7 & - & 99.4 & 51.5 & 48.4 & 2,550 \\
\hline 9.2 & 1.3 & 2.1 & - & 100 & 66.1 & 31.9 & 2,260 \\
\hline 9.3 & 1.2 & 2.2 & - & 100 & 69.2 & 19.2 & 2,220 \\
\hline 9.6 & 1.0 & 2.4 & - & 100 & 75.9 & 1.2 & 1,930 \\
\hline 9.8 & 0.7 & 2.8 & - & 100 & 64.6 & - & 1,580 \\
\hline 7.8 & 0.1 & 2.5 & 0.8 & 100 & 97.3 & - & 1,820 \\
\hline
\end{tabular}

Similar studies were conducted for STF and ammonium bifluoride, eqns (8), (16).

\subsection{Pilot facility}

To study the DUHF processing according to eqn (5), at the Siberian Chemical Combine, JSC, Seversk, Tomsk Region, Russian Federation, we constructed a pilot facility whose diagram is given in Fig. 2.

The main element of the facility is the "combustion tunnel"-type thermostated reactor 1 with an inner diameter of $150 \mathrm{~mm}$ made of nickel alloy and equipped with a multi component nozzle 2 of a special design, flow temperature measuring systems using thermocouples, and optical sensors. The flame front is initiated using a pilot flame based on self-igniting components - ammonia and fluorine. The facility is equipped with a system for feeding gaseous components into reactor 3, heat exchangers 4 and 5, a cyclone 6 , a set of nickel ceramic filters 7, and a process product condensation system 8 and 9. The maximum UHF flow rate is $10 \mathrm{~g} \cdot \mathrm{s}^{-1}$.

\section{HYDROFLUORIC ACID DEHYDRATION}

The process products according to eqn (4) can contain water; therefore, we conducted studies on producing HF from its aqueous solutions - by high-temperature water reduction with carbon in the presence of hydrogen fluoride [4], hydrofluoric acid dehydrogenation with sulfuric acid and sodium fluoride, etc. 


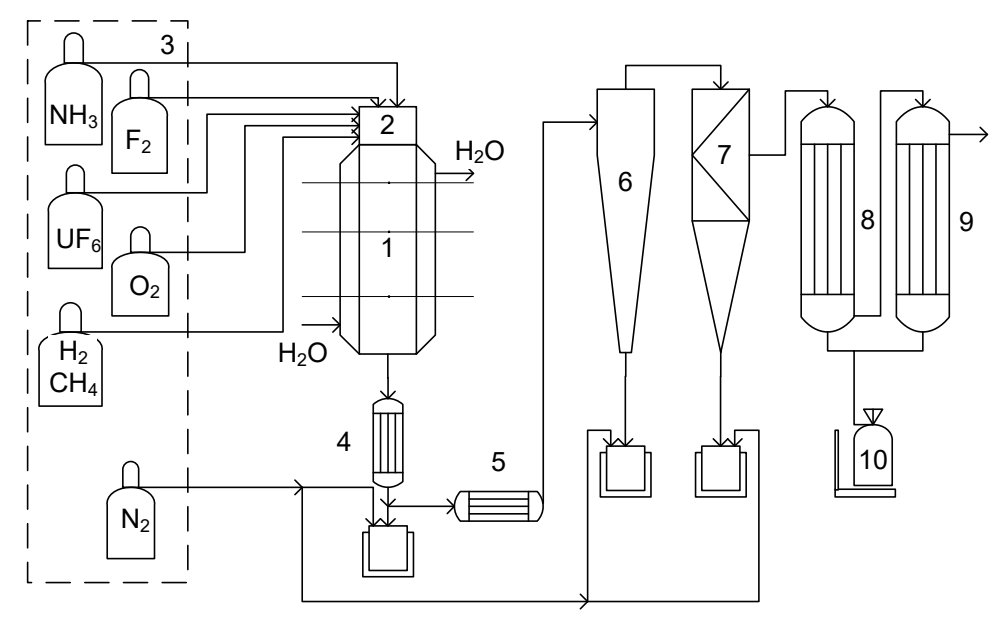

Figure 2: Diagram of the pilot facility for processing UHF in a flame of hydrogencontaining fuel, and oxygen-containing oxidant.

\section{COMPARISON OF AHF PRODUCTION COSTS USING THE CONVENTIONAL AND SUGGESTED METHODS}

In the conventional method for AHF production according to eqn (1), the fluorine-containing raw material is concentrate of natural calcium difluoride. In the structure of the AHF production cost, the share of calcium difluoride is $50-60 \%$.

In the proposed AHF production method, fluorine-containing raw materials are wastes and by-products of modern industries, accumulated and annually replenished, whose contribution to the AHF cost structure can be zero or even negative. Other raw materials are cheap and accessible substances: methane, ammonia, hydrogen, oxygen, calcium oxide, carbon, sulfuric acid.

In addition, the implementation of the suggested method does not require any exclusive construction materials, as, for example, is the case of implementing the DUHF processing method by the Areva Company. This is due to the fact that the high temperature is achieved in the reaction zone through the inner heat release of the system, rather than through heating by equipment walls.

Therefore, we can expect about a twofold decrease in the AHF production cost when using the method suggested for its production, without taking into account the environmental benefits associated with reduced amount of stored toxic substances and low-hazard materials placed on waste landfills.

\section{CONCLUSION}

We suggested a universal method for fluorine generation from industrial fluorine-containing by-products and wastes generated in NFC, production of phosphate fertilizers, rare metals, aluminum, freons, electronic gases, fluoropolymers, etc.

The essence of the method is in processing fluorides in a flame of hydrogen-containing fuel and oxygen-containing oxidant with generation of hydrogen fluoride.

Thermodynamic calculations were carried out that allowed us to substantiate the suggested method for many fluorine-containing substances: $\mathrm{UF}_{6}, \mathrm{SiF}_{4}, \mathrm{NH}_{4} \mathrm{~F} \cdot \mathrm{HF}, \mathrm{Na}_{3} \mathrm{AlF}_{6}$, $\mathrm{CF}_{4}, \mathrm{SF}_{6}, \mathrm{NF}_{3}$, etc. 
We constructed a laboratory facility with a "combustion tunnel"-type reactor, at which we carried out experiments with $\mathrm{CF}_{4}, \mathrm{NF}_{3}, \mathrm{SiF}_{4}, \mathrm{NH}_{4} \mathrm{~F} \cdot \mathrm{HF}$, the results of which confirmed the expediency of applying the suggested method for producing hydrogen fluoride from fluorinecontaining wastes.

A pilot facility has been created to study $\mathrm{UF}_{6}$ processing using the suggested method.

We investigated various methods for producing hydrogen fluoride from its aqueous solutions, which can be by-products of fluoride processing in a flame of hydrogen-containing fuel and oxygen-containing oxidant.

The commercial feasibility of implementing the suggested method lies in about a twofold decrease in the AHF production cost and in minimizing environmental hazards.

The developed method for producing hydrogen fluoride may be an alternative of the only industrial method of obtaining hydrogen fluoride from natural calcium difluoride by its sulfuric acid decomposition.

Now on the basis of the proposed method a project to create commercial DUHF processing plant at JSC Siberian chemical combine with a capacity of several thousand tons of AHF per year is being developed.

Also the negotiations to commercialize the technology for producing AHF from AHFA are underway with Russian producers of phosphate fertilizers.

\section{ACKNOWLEDGEMENT}

The work was financially supported by the SKOLKOVO Innovation center.

\section{REFERENCES}

[1] The Essential Chemical Industry, Hydrogen fluoride. www.essentialchemicalindustry.org/chemicals/hydrogen-fluoride.html. Accessed on: 14 Nov. 2017.

[2] Shatalov, V., Seredenko, V., Kalmakov, D., Ivanov, A., Gromov, O. \& Parfenov, A., Depleted uranium hexafluoride: the fluorine source for production of the inorganic and organic compounds. Journal of Fluorine Chemistry, 130(1), pp. 122-126, 2009. DOI: 10.1016/j.jfluchem.2008.07.025.

[3] Tumanov, Y.N., Plasma and High-Frequency Processes for Obtaining and Processing Materials in the Nuclear Fuel Cycle: Present and Future, Fizmatlit: Moscow, pp. 412465, 2003.

[4] Borgard, J., Herbelet, F. \& Gwinner, B., Recycling hydrofluoric acid in the nuclear industry: The over Azeotreopic flash process (OVAF). Journal of Fluorine Chemistry, 185, pp. 17-23, 2016. DOI: 10.1016/j.jfluchem.2016.03.001.

[5] Morel, B. \& Duperret, B., Uranium and fluorine cycles in the nuclear industry. Journal of Fluorine Chemistry, 130(1), pp. 7-10, 2009. DOI: 10.1016/j.jfluchem.2008.05.022.

[6] The Essential Chemical Industry, Phosphoric Acid. www.essentialchemicalindustry.org/chemicals/phosphoric-acid.html. Accessed on: 25 Jan. 2016.

[7] Dahlke, T., Ruffiner, O. \& Cant, R., Production of HF from H2SiF6. Procedia Engineering, 138, pp. 231-239, 2016. DOI: 10.1016/j.proeng.2016.02.080.

[8] Agulyansky, A., The Chemistry of Tantalum and Niobium Fluoride Compounds, Elsevier: Amsterdam, pp. 11-56, 2004.

[9] Kulikov, B.P. \& Istomin, S.P., Recycling of Aluminum Production Waste, Maneb: St Petersburg, pp. 9-112, 2004.

[10] Maximov, B.N. et al., Industrial Organofluorine Products, Khimiya: St Petersburg, pp. 14-187, 1996. 
[11] Pashkevich, D. et al., A method of obtaining anhydrous hydrogen fluoride from its aqueous solutions using reduction of water by carbon. Proceedings of the 21st International Symposium on Fluorine Chemistry, p. 60, 2015.

[12] Zimin, A. \& Pashkevich, D., Thermodynamic basis of uranium hexafluoride recovery in the combustion mode. Proceedings of the Jubilee Conference of the National Committee of RAS for Heat and Mass Transfer "Fundamental and Applied Problems of Heat and Mass Transfer”, 2, pp. 25-26, 2017.

[13] Pashkevich, D., Methods of industrial fluorine compounds production with depleted uranium hexafluoride using. Proceedings of the V International Conference-School on Chemical Technologies, 2, pp. 433-435, 2016. 